\title{
Using TRIZ10 for enhancing creativity in engineering design education
}

\author{
Juan David Cano-Moreno ${ }^{1}$ (D) . José Manuel Arenas Reina ${ }^{1}$. \\ Francisca Victoria Sánchez Martínez ${ }^{1}$. José María Cabanellas Becerra²
}

Accepted: 31 August 2021 / Published online: 21 September 2021

(c) The Author(s) 2021

\begin{abstract}
One of the popular creativity methods to solve technical problems is the Theory of Inventive Problem Solving, (TRIZ), however, requires a considerable investment of time. A teaching methodology for a simplified version of TRIZ (TRIZ10) has been developed for reducing learning time and improving the creative process in solving technical problems. This method has been applied in a small group of engineering design students as a proof of concept. The evaluation of the results obtained shows that students achieved adequate learning of this creative technique ( $75 \%$ overall efficiency). This method has led to the doubling of the number ideas developed by students compared to those generated before learning TRIZ10; further, it also improves a $10 \%$ the average degree of novelty for these ideas.
\end{abstract}

Keywords Creativity $\cdot$ TRIZ $\cdot$ Teaching methods $\cdot$ Technical innovation $\cdot$ Engineering design

\section{Introduction}

The increasing competence between different companies requires engineers to generate creative and innovative solutions quickly and continuously. Although the concept of creativity has evolved throughout history (Cano-Moreno \& Cabanellas Becerra, 2018a; Sternberg \& Lubart, 1998; Tatarkiewicz, 2004), it broad understanding today emerged largely as a result of the efforts of pioneers Guilford (1950) and Torrance (1962). Guilford described creativity in the $50 \mathrm{~s}$ as a sensitivity to problems, as divergent thinking, and as an ability to generate multiple ideas, new patterns, and transformation of knowledge and meaning, and to use objects for new functions. In 1962, Torrance defined creativity as a pr ocess that, including the definition of Guilford, ends up testing those ideas and, possibly, modifying and retesting the initial ideas.

Juan David Cano-Moreno

juandavid.cano@upm.es

1 E.T.S. de Ingeniería y Diseño Industrial, Universidad Politécnica de Madrid, C/ Ronda de Valencia, 3, 28012 Madrid, Spain

2 E.T.S. de Ingenieros Industriales, Universidad Politécnica de Madrid, Madrid, Spain 
Creative and innovative solutions today need to be competitive and must follow these definitions and new practices, to be commercialized (innovative). To this end, engineering students need to be trained in the use of tools that can help them accelerate the process of solving technical problems (Belski, 2015; Bourgeois-Bougrine et al., 2017; Bozkurt Altan \& Tan, 2020; Corazza \& Agnoli, 2018; Ranjan et al., 2018; Turner, 2009). These tools include creativity techniques that help break the psychological inertia inherent in human beings. Part of this inertia can be explained by the somatic marker hypothesis (Poppa \& Bechara, 2018), which states that we have predetermined ideas to which we return on a recurring basis. According to Sternberg's research (Sternberg 2006), creativity training improves results compared to classical education that only includes synthetic, analytical, or practical skills.

In engineering design it has already been used different creativity techniques and approaches (Lee et al., 2019; Litcanu et al., 2015; Sancibrian et al., 2019; Thompson \& Lordan, 1999; Wu \& Wu, 2020) to explore design solution space (S. Daly et al., 2012a, 2012 b). Brainstorming starts from a blank state and provides very general rules: suggest as many ideas as possible, avoid evaluating while generating and build off other ideas. Others techniques guide the idea generation process based on different approaches, but with a common objective, that is to break the psychological inertia. SCAMPER (Thompson \& Lordan, 1999) suggest 7 transformations to existing concepts (Substitute, combine, adapt, modify, put to other purposes, eliminate and rearrange). Design Heuristics (Daly et al., 2012a, 2012b) method is grounded in studies of designers. This method uses cognitive prompts that point designers towards design solution space (e.g. apply an existing mechanism in a new way). Design Thinking (Ling, 2015) consists on an iterative process developed by designers focussed on a problem with 5 stages (empathise, define, ideate, prototype and tests), generating ideas as solution of this problem and then testing those ideas. 6-3-5 method(Higgins, 1994), also called Brainwriting 6-3-5, can be used a part of other creative techniques, such as Design Thinking. This method consists of generating ideas in a group of 6 participants. Firstly, each participant have to generate 3 ideas and then, the other participants have to extend the ideas of the others within 5 iterations. Analogy is also another important method for ideation in design (Moreno et al., 2014). In this method, the idea generation for solving problems is based on similarities and could be divided in two steps of mapping from source to abstraction and from abstraction to the new design (Goldschmidt, 2001).

Among the best known and applied creativity techniques to solve technical problems, we have TRIZ (Altshuller, 2002), which is a Russian acronym that can be translated as " Theory of Inventive Problem Solving ". TRIZ has been used for automating the creative process in the field of engineering (Arcidiacono \& Bucciarelli, 2016; Chang et al., 2016). The use and advantages of TRIZ in the generation of ideas is documented in several investigations (Belski et al., 2013; Bertoncelli et al., 2016; Borgianni et al., 2018; Chang et al., 2016; Cortes Robles et al., 2009, p.; Dumas et al., 2016; Dumas \& Schmidt, 2015; Gray et al., 2019).

This technique was created by a Russian engineer Genrich Altshuller between 1946 and 1985. Altshuller was working in the patent office of the Russian Navy, where after analyzing several thousand patents, he identified a series of common principles applied to solving similar problems. These principles are called inventive principles and suggest a means to find the solution to a technical contradiction, wherein the improvement to the system results in degradation of another characteristic of the system. The contradiction matrix (Altshuller, 2002; "SolidCreativity (2014), TRIZ Matrix, Contradictions table, overcome contradiction with TRIZ" n.d.), one of TRIZ's most used tools, 
includes up to four principles that can be applied to each contradiction formulated based on 39 parameters.

Indeed, it is necessary to quantify the value that creativity brings to classic problemsolving processes. Several metrics and objective methods of measuring both personal creativity and the ideas generated have been published (Oman et al., 2013). Both are related in the research of Toh and Miller (2016), where they conclude that engineering students with greater awareness, kindness, and tolerance for ambiguity generate more novel ideas. Further, their study also highlights the difficulty of arriving at a novel final design because of the tendency towards a conservative initial selection of concepts to be developed. Thompson and Lordan (1999) provide an exhaustive review on the concept of creativity from other research and distinguish four influential fields in creativity: person, process, product, and environment.

Diedrich et al. (2015) show how creativity can be valued through its novelty and usefulness through 18 independent judges. They conclude that novelty can be considered a factor of greater order than utility in predicting creativity. Oman et al. (2013) collected various methods to measure the creativity of a product via the use of metrics and judges. They also propose two methods for evaluating the creativity of a product, comparative evaluation of creativity (CCA) and multipoint creativity evaluation methods (MPCA). Ranjan et al. (2018) proposed a method for measuring creativity at different stages of engineering design based on two indicators: novelty and satisfaction of requirements.

Creativity associated with the use of a particular creative technique was measured in other research studies. For the assessment of the use of TRIZ, Livotov et al. (2018) developed an approach for evaluating the efficiency of TRIZ in process intensification (IP) through six cases and by analyzing compliance with objectives, impact of secondary problems, and the variety and efficiency of ideas generated as a solution. Belski et al. (2013), in a study conducted at the Royal Institute of Technology in Melbourne (RMIT) over 5 years, found an improvement in self-efficacy in solving problems between the unit used by TRIZ versus a classical engineering unit. In a shorter six-week study, Chang et al. (2016) showed the benefits of using TRIZ in a study of 121 university students, who improved their creativity and developed and implemented better novel ideas.

The documented benefits of the use of TRIZ justify its teaching use for engineering students. Table 1 summarizes the capacitation times and main outcomes of other authors in relation to TRIZ teaching experiences. In general, TRIZ instruction substantially increases the degree of novelty of the ideas generated.

However, learning is complex if you only want to use it as part of a subject. Ilevbare et al. (2013) review the strengths and challenges of using TRIZ. The challenges include points such as poor understanding of TRIZ tools, lack of standardization of the learning process, non-homogeneous interest in the tool, and the time spent on learning is very high.

Therefore, to facilitate the use of TRIZ easily and quickly, we recommend teaching a simplified version, TRIZ10 (Cano-Moreno \& Cabanellas Becerra, 2018b). The method of the simplified use of TRIZ, derived from the results presented by Cano-Moreno \& Cabanellas Becerra, 2018a), in which the great asymmetry in the probability of use of each of the 40 inventive principles of the contradiction matrix is shown. Thus, in $50 \%$ of the cases resolved with this matrix, one of the 10 inventive principles contained in the TRIZ10 methodology will have to be used. These principles will guide idea generation for exploring solutions space. They have similarities with SCAMPER transformations (e.g. Substitute and the inventive principle replacement of mechanical system used on TRIZ10) and from each inventive principle can be derived several design heuristics (Tessari \& De Carvalho, 2015). 


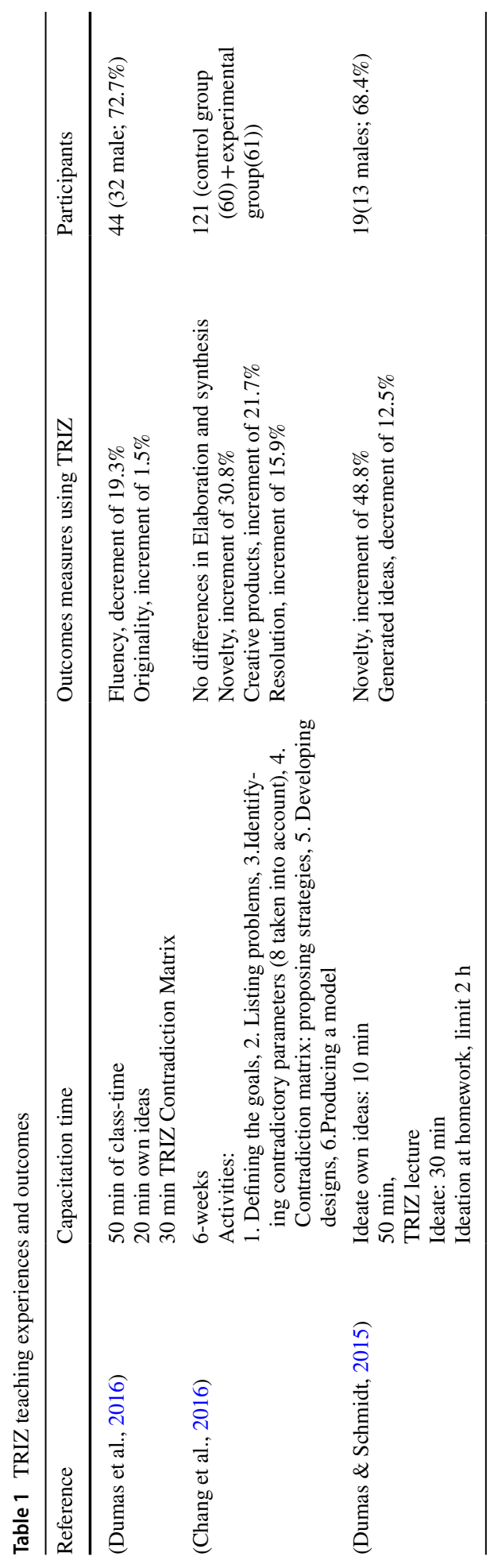


Given the teaching difficulties presented by the complete TRIZ method and the lack of proposals to facilitate its learning by simplified methods, a teaching method based on TRIZ10 approach was developed in this study. The application of this proposed method is expected to help improve the process of solving technical problems. Further, to verify the potential validity of the proposed method, the method is applied trough individual and group tasks to a small group of 13 students (Higher Technical School of Engineering and Industrial Design of the Polytechnic University of Madrid) for the subject "Design and Creativity Methodology", which is part of the degree course for "Design and product development engineering". The students are around 20 years old ( 7 female; $53.8 \%$ ) and the subject is on the second year of this degree.

\section{Methodology}

This methodology aims to make creative engineers. Scott et al. (2004) studied the importance of creativity training and some conclusions argue that creativity training should be based and sound, it has to be demonstrate the relation with the real world and the training should be followed with appropriate exercises to provide people with practice in applying relevant strategies and heuristics.

This methodology follows some of the recommendations of Scott et al. (2004), such as looking for solid training in TRIZ10, which is immersive and employs learning through exercises. Following the conclusions presented in other research (Deci \& Ryan, 2012; Gray et al., 2019; John-Steiner \& Mahn, 1996; Vygotsky, 2004), the teaching process of TRIZ10 starts once students have used their own resources to solve a proposed problem. The problem is proposed and must be resolved as a job to be performed in groups of $4 / 5$ students.

Although this methodology is mainly developed for engineering students, it could be extended to other student levels adapting times and problems. In this work, "students" refer to engineering students.

This creativity technique was taught using expository techniques and through exercises for more effective training of creativity that, as defending Scott et al. (2004), is in line with the stimulus most employed, thus creating more effective creativity training.

The developed methodology is applied to a pilot group of students in the subject of "Design methodology and creativity". This subject consists of a total of 4.5 ECTS (European Credit Transfer and Accumulation System (2018)) credits and is taught in the second semester of the second course of the degree "Engineering Degree in Industrial Design and Product Development," at the Higher Technical School of Engineering and Industrial Design of the Polytechnic University of Madrid.

This course for this subject is divided into theory and practical classes. In the practical classes, students are guided to improve their individual creative qualities in a practical way. Individual improvement is useful in the search for solutions that students, already organized in groups, propose for an unsolved problem that they also look for and select. In these practical classes of the subject is where the application of the described methodology is framed. For this, a small test group has been selected, with a total of 13 students, which will be organized into three subgroups of 5, 4, and 4 students, respectively. On the one hand, each student will perform activities proposed by the methodology individually (Activities 1 to 5), and on the other hand, each group will propose a problem to solve and generate solutions as described in the proposed methodology (Sessions 01 to 04). 
Next sections start describing TRIZ10 approach. After, the time schedule and proposed activities that form the developed methodology are described such that they involve and engage the students to the fullest. Finally, evaluation methods are described.

\section{TRIZ10 approach}

TRIZ10 approach comes from a probabilistic analysis of classic contradiction matrix of TRIZ. This study (Cano-Moreno \& Cabanellas Becerra, 2018a) shows that for a random inventive problem formulated with this matrix, the probability to find an inventive principle is very different for each one of the 40 classic principles. Table 2 shows the individual probability of each inventive principle ranked from the most probable inventive principle, that is the number 35, Transformation of properties. This inventive principle has a probability of more than $10 \%$ of appearing in an inventive problem formulation using the Contradiction Matrix.

TRIZ10 (Cano-Moreno \& Cabanellas Becerra, 2018b, p. 10) suggest using the 10 first inventive principles from these have a cumulative probability of more than $50 \%$. The cost/ benefit rate is very low due to $25 \%$ of inventive principles covers the more than $50 \%$ of possible Contradiction Matrix cells. TRIZ10 creativity approach or technique can be defined as a brainstorming inspired on TRIZ10 inventive principles.

\section{Proposed teaching activities}

The methodology of learning and implementation of TRIZ10 is developed over four consecutive weeks wherein the teacher conducts a $2 \mathrm{~h}$ session every week in the class. As shown in Fig. 1, there are a total of four sessions, from Session 01 to Session 04, for generating ideas in groups. These groups will remain invariable throughout the course. There are two sessions for each different approach (Own ideas and TRIZ10). During TRIZ10, there are four activities, $A_{i}$ and $0.5 \mathrm{~h}$ for TRIZ10 approach teaching. TRIZ10 instruction includes several teaching techniques such as exposition, the use of the question technique and an explanation guided by examples of each of the 10 inventive principles used by TRIZ10 (e.g., for "preliminary action": Open-easy to cookies or a milk carton, leave ingredients on hand before cooking).

At last, the usage of the classic contradiction matrix is explained and students make the activity $5, A_{5}$, at home. All activities were doing at home and each student spent the necessary time to solve it, but it wasn't limited or measured.

This schedule starts once the students have selected a problem to solve in groups. In the first two sessions, sessions 01 and 02 , the students generate in groups their own solutions via "brainstorming". They spend a total of $3.5 \mathrm{~h}$ in these two sessions. In these sessions, each group works generating ideas for solving their problems. They collect each idea, without discard anything. Students are encouraged to draw in anywhere (paper, class blackboard, portable...) for all creativity sessions. Then, the components of the TRIZ10 creativity technique are explained assuring that students understand the meaning of each 10 inventive principles. After performing the first two activities, A1+A2, the first session of generating ideas based on this creativity technique is developed. The following describes these proposed individual activities to enhance the learning of TRIZ10:

- Activity 1. Performing a visual TRIZ10. Each student has to draw, using the method they choose, an icon for each of the 10 inventive principles that TRIZ10 includes 


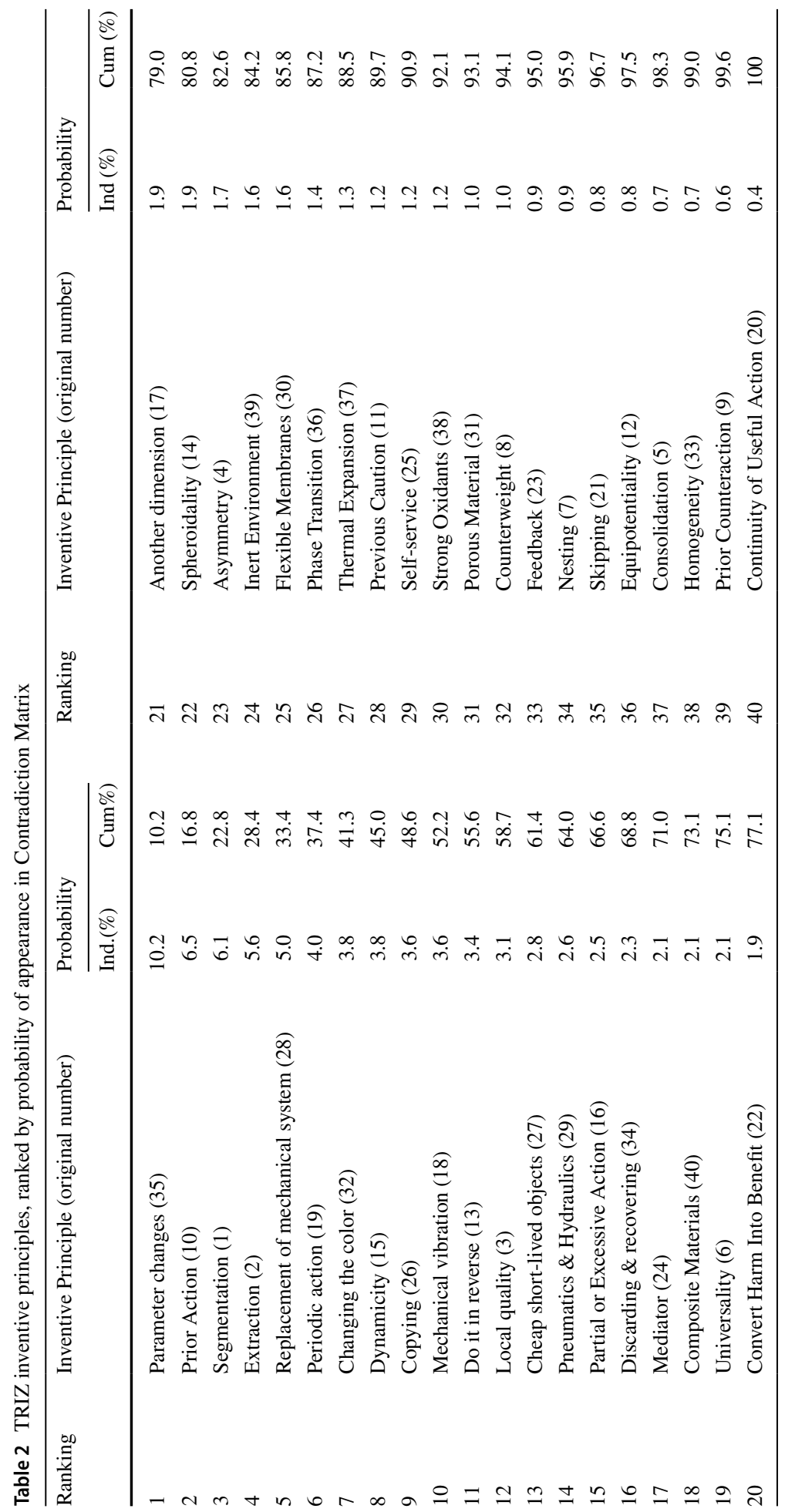




\begin{tabular}{|c|c|c|c|c|c|c|c|c|c|c|c|c|c|c|c|c|c|c|c|}
\hline \multirow{2}{*}{\multicolumn{2}{|c|}{$\begin{array}{c}\text { Classes/Days } \\
\text { Hours }\end{array}$}} & \multicolumn{4}{|c|}{ Day 1} & \multicolumn{4}{|c|}{ Day 2} & \multirow{2}{*}{ H } & \multicolumn{4}{|c|}{ Day 3} & \multirow{2}{*}{ H } & \multicolumn{3}{|c|}{ Day 4} & \multirow{2}{*}{ H } \\
\hline & & 0,5 & 1 & 1,5 & 2 & 2,5 & 3 & 3,5 & 4 & & 4,5 & 5 & 5,5 & 6 & & 7 & 7,5 & 8 & \\
\hline Oun Idore & Session 01 & & & & & & & & & & & & & & & & & & \\
\hline Own Ideas & Session 02 & & & & & & & & & & & & & & & & & & \\
\hline \multirow{5}{*}{ TRIZ10 } & Training & & & & & & & & & & & & & & & & & & \\
\hline & $A 1+A 2$ & & & & & & & & & & & & & & & & & & \\
\hline & Session 03 & & & & & & & & & & & & & & & & & & \\
\hline & $A 3+A 4$ & & & & & & & & & & & & & & & & & & \\
\hline & Session 04 & & & & & & & & & & & & & & & & & & \\
\hline \multirow{2}{*}{ TRIZ } & Training & & & & & & & & & & & & & & & & & & \\
\hline & A5 & & & & & & & & & & & & & & & & & & \\
\hline H & \multicolumn{4}{|c|}{ Done at home } & & & & & & & & & & & & \multicolumn{4}{|c|}{ Where } \\
\hline \multirow{3}{*}{\multicolumn{14}{|c|}{$\begin{array}{l}A_{i}, i(i=1 \ldots 5), \text { individual activities } \\
\text { Session } 0 j,(j=1 \ldots 4), \text { generation of ideas times (in groups) }\end{array}$}} & & & \multicolumn{2}{|c|}{ Class } & \multicolumn{2}{|c|}{ Home } \\
\hline & & & & & & & & & & & & & & \multirow{2}{*}{$\stackrel{+\pi}{\stackrel{N}{\infty}}$} & Own Ideas & & & & \\
\hline & & & & & & & & & & & & & & & TRIZ10 & & & & \\
\hline
\end{tabular}

Fig. 1 TRIZ10 schedule

(Cano-Moreno \& Cabanellas Becerra, 2018b, p. 10). Table 3 shows the 10 inventive principles of TRIZ10, its correspondence with the number used for that principle in the classic TRIZ, in addition to its meaning. The drawings of the TRIZ10 principles will constitute a visual map that will inspire students in group brainstorming sessions by helping them to remember and find solutions based on them.

- Activity 2. Looking for and describing three daily technical problems whose solution includes some of the 10 inventive principles of TRIZ10 as the main solution mechanism. The students had to include a hand sketch of the problem and the solution.

With these activities were conducted, following learning phases described by Shuell (1990), is expected that students have increased their level of automaticity of TRIZ10 inventive principles usage. After these activities, the second session is started.. In this session, the generation of ideas that solve their problem is proposed, based on the principles of TRIZ10. Each student group has their visual TRIZ10 in front of them to be inspired by the 10 principles. Each idea generated by the group is indicated in a table, which indicates the principle or principles (from 1 to 10) that have inspired the idea. This classification of ideas is carried out by the members of each group. Ideas that are not based on these principles are also added.

After this first phase of generating ideas in session 02, students must do two other activities at home to continue their training and internalization of the TRIZ10 technique. These are activities 3 and 4, as described below.

- Activity 3. It is intended to generate ideas around and existing and common object (Tupperware, clothe hanger, clip, glass...). In this case, the selected object was a Tupperware for all students. Then, students are asked to generate at least 10 innovative ideas about the indicated object; these ideas should explain the object and must be based on at least one of the 10 principles of TRIZ10 (can be combined, but It is necessary to indicate which / how many have been used). Further, the students are asked to create a manual sketch of the three solutions they select. Table 4 shows the table that students have to fill in this activity. Some real examples from students about the object 


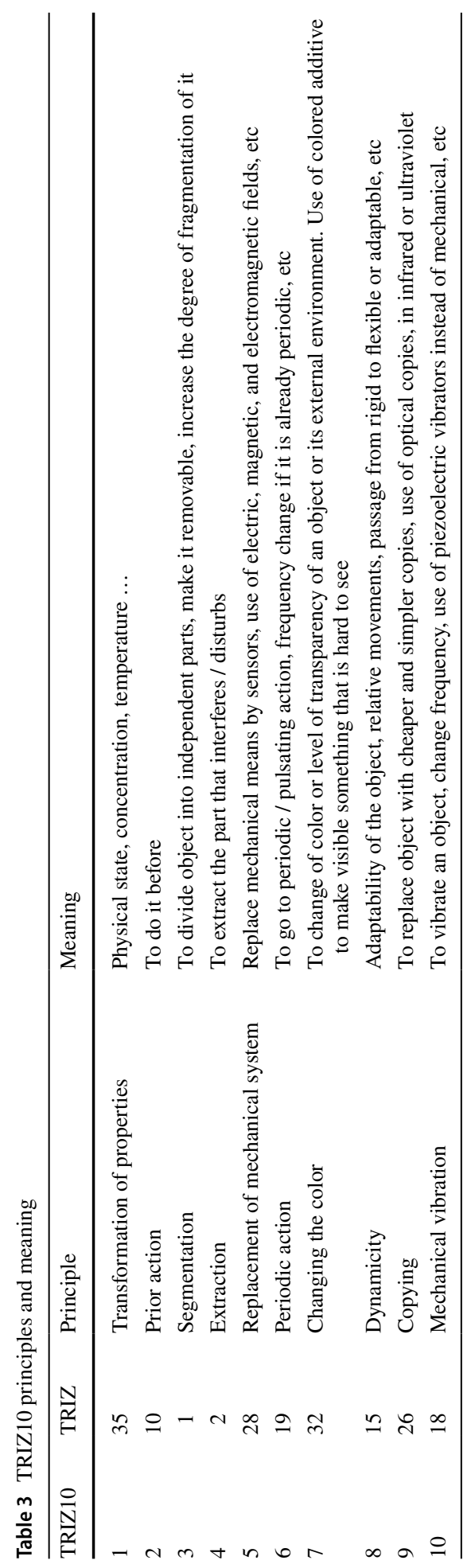




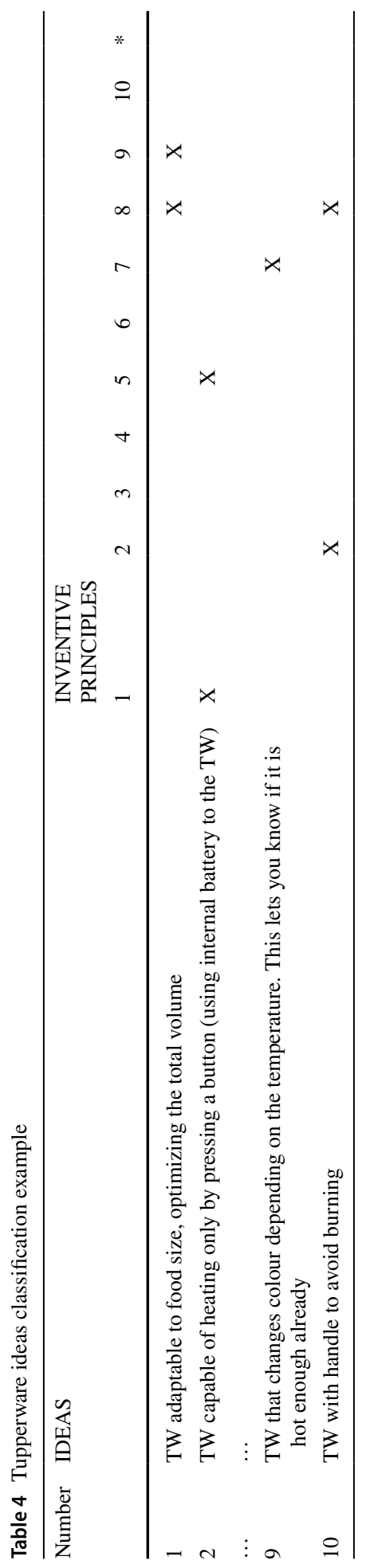


Tupperware (TW) have been collected. Idea number 1, a TW adaptable to food size. It is inspired by principles 8 and 9 . Principle 8 , dynamicity, calls for making objects more flexible, something present in a TW that adapts its size and, principle 9, copying, is used when adapting the TW to the shape of the food, copy its shape.

- Activity 4. A problem with a clear technical contradiction is proposed, which must be solved using only one or more of the inventive principles of the TRIZ10 approach. A technical contradiction occurs when improving something of the technical system, another characteristic deteriorates.

After delivering these activities, the second set of sessions of generating ideas based on TRIZ10 is started (sessions 03 and 04). Each group writes ideas in a new table-the same as that in the last session-but associated with this new session. Students continue to use the TRIZ10 visual map generated in Activity 1.

\section{Evaluation of activities: Efficacy indicators}

The motivation and involvement of students in a task is vital to the success of learning and using TRIZ10. A series of indicators generated are then proposed to assess the success of each activity proposed to students as part of their training and immersion in the TRIZ10 creativity technique. These indicators also make it possible to distinguish activities that should be improved to increase the learning effectiveness of this creative technique. These indicators, $\eta_{A k}$, will be called " $k$ activity efficiency" and their value is set between 0 and 1 .

- Activity 1. As a measure of the effectiveness of this activity, $\eta_{A 1}$ indicates the average similarity of each of the 10 drawings to the underlying concept of each principle. This assessment, although somewhat subjective, was conducted by the teacher of the subject, after checking whether each principle clearly was clearly represented by its drawing. The 10 drawings of each student were analyzed and a $P 1_{i j}$ value between 0 and 1 will be assigned to each drawing, where $i$, is the drawing number and $j$ is the student number. The punctuation has been divided into three levels, depending on how fast and close the student image represent the corresponding inventive principle: $0,0.5$ and 1. Thus, the value of $\eta_{A 1}$ can be obtained by

$$
\eta_{A 1}=\frac{\sum_{i=1}^{i=N} \sum_{j=1}^{j=10} P 1_{i j}}{10 N}
$$

- Activity 2. The correctness or otherwise of the application of the selected principle to the everyday problem solving is evaluated. This value, $P 2_{i j}$, is between 0 and 1 . Let $N$ be the number of students; then, as each one proposes and solves three problems, there are a total of $3 \mathrm{~N}$ problems. The assessment of good resolution and, therefore, a medium understanding of the principles is called the effectiveness of activity $2, \eta_{A 2}$. If $i$ is the number of students and $j$ is the number of problems to be delivered by each student, the $\eta_{A 2}$ is obtained by

$$
\eta_{A 2}=\frac{\sum_{i=1}^{i=N} \sum_{j=1}^{j=3} P 2_{i j}}{3 N}
$$


Information is also obtained on the principles most used by students, based on the frequency of use. This knowledge will provide information on what it is difficult for them to relate their application to everyday life.

- Activity 3. The degree of learning of this activity can be measured through effectiveness, $\eta_{A 3}$, which measures the average of the percentage of different principles that students have used in the generation of uses other than the proposed object. If $P 3_{i}$ is the number of different principles used by the $i$-student, then for $\mathrm{N}$ students, the effectiveness of this activity is formulated as

$$
\eta_{A 3}=\frac{\sum_{i=1}^{i=N} P 3_{i}}{10 N}
$$

- Activity 4. As this case, each student solution will be valuated within a range from 0 to 10 , taking into account if the solution solve or not the problem in an easy way and if the TRIZ10 inventive principles are properly selected and applied. The average grade, expressed on a per unit basis, is defined as the effectiveness for this activity, $\eta_{A 4}$.

$$
\eta_{A 4}=\frac{\sum_{i=1}^{i=N} P 4_{i}}{10 N}
$$

The overall effectiveness of this learning process of TRIZ10, $\eta_{g}$, can be measured as the fourth root of the product of partial efficiencies, using the following expression. It has been used geometric mean instead arithmetic one because it is more conservative and homogenizes the higher and lower values.

$$
\eta_{g}=\sqrt[4]{\prod_{i=1}^{i=4} \eta_{A i}}=\sqrt[4]{\eta_{A 1} \cdot \eta_{A 2} \cdot \eta_{A 3} \cdot \eta_{A 4}}
$$

\section{Added value of TRIZ10}

In this section, two metrics are developed to quantify the added value of TRIZ10 to the process of solving technical problems. As in other investigations (Dumas et al., 2016; Gray et al., 2019), the fluency and degree of practical novelty of the ideas generated is measured. The added value provided by TRIZ10 in these two components of the creative process will also be measured quantitatively. These values will be compared with those obtained by the classical method, by asking students to use only their own resources, without the knowledge of this creativity technique.

\section{Fluency}

In creative terms, fluency measures the number of ideas generated. To assess the influence of the use of TRIZ10 on this characteristic, the added value us defined owing to the use of this technique as the number of new ideas generated, $\Delta I$, among the number of previous ideas, $I_{0}$, as shown in

$$
\Delta V_{f}=\frac{\Delta I}{I_{0}}
$$


Considering that there have been two brainstorming sessions, based on TRIZ10, we have the values added by each of these two sessions according to the following mathematical formulation. If we use subscripts 01 and 02 for the first and second TRIZ10 based sessions (sessions 03 and04), the added values of each session are

$$
\Delta V_{f_{01}}=\frac{\Delta I_{01}}{I_{0}} ; \quad \Delta V_{f_{02}}=\frac{\Delta I_{02}}{I_{0}+\Delta I_{01}}
$$

To obtain a global added value, $\Delta V_{f}$, of the applied creativity technique TRIZ10, it is necessary to include all ideas generated in both sessions $\left(\Delta I_{01}+\Delta I_{02}\right)$ and to compare them with those that were initially obtained, $I_{0}$.

$$
\Delta V_{f}=\frac{\Delta I_{01}+\Delta I_{02}}{I_{0}}
$$

By combining Eqs. (8) and (9), this global added value can be expressed as a function of partials given by

$$
\Delta V_{f}=\Delta V_{f_{01}}+\Delta V_{f_{02}}+\Delta V_{f_{01}} \cdot \Delta V_{f_{02}}
$$

In general, if we would have $\mathrm{k}$ processes of generating ideas in addition to the initial one, a total number of ideas, $I_{T}$, would be generated according to the following equation

$$
I_{T}=I_{0} \cdot\left(1+\Delta V_{f_{01}}\right) \cdot\left(1+\Delta V_{f_{02}}\right) \cdots\left(1+\Delta V_{f_{0 k}}\right)=I_{0} \cdot \prod_{i=1}^{i=k}\left(1+\Delta V_{f_{0 i}}\right)
$$

A global added value can also be defined as

$$
\Delta V_{f}=\frac{I_{T}-I_{0}}{I_{0}}
$$

Substituting Eq. (11) in the Eq. (10), we get the following general expression of the added value to a process of generating ideas with $\mathrm{k}$ sessions in addition to the initial value:

$$
\Delta V_{f}=\frac{I_{T}-I_{0}}{I_{0}}=\frac{I_{0} \cdot \prod_{i=1}^{i=k}\left(1+\Delta V_{f_{0 i}}\right)-I_{0}}{I_{0}}=\left[\prod_{i=1}^{i=k}\left(1+\Delta V_{f_{0 i}}\right)\right]-1
$$

\section{Practical novelty}

A simplified method is developed to assess the "practical novelty" of the ideas generated and thereby determine the value of practical novelty added, and thus compare ideas the generated before and after teaching students the creative technique TRIZ10. Other authors (Sarkar \& Chakrabarti, 2011) have also used methods based on usefulness and novelty in evaluating the creativity of designs. For this, all ideas generated to solve each problem have been listed and assessed on the scale 1-3-5-7-9 by three different teachers (two men and a woman) who did not previously know the work of the groups. The works were evaluated by three professors with extensive experience in engineering design. This evaluation team was made up of a full professor from the Polytechnic University of Madrid and Director of the research group "Industrial Design and Manufacturing" at UPM (with 35 years of teaching and research experience in engineering and industrial design) and two associate professors from UPM with more than 25 years of teaching and research experience in this field. 
Only one of the associate professors teaches the subject where this proof of concept has been carried out. Teachers, individually and based on their experience, have evaluated an idea with a higher score for novel ideas that were realizable, and hence, the name "practical novelty". In addition, the ideas shown to the evaluators have been placed in alphabetical order. Thus, a non-biased evaluation of the practical novelty of these ideas is ensured.

Once this evaluation by the three professors is complete, the average value of practical novelty $n_{j}$ is obtained for each $\mathrm{j}$-idea. If you add that average novelty value to your own ideas, generated before knowing TRIZ10, you have the novelty index $N_{\text {own }}$. Similarly, the practical novelties of the ideas generated in the first and second sessions of TRIZ10, $N_{T 10_{1 s t}}$ and $N_{T 10_{2 n d}}$ are defined. The total novelty value of the sessions obtained by applying TRIZ10, $N_{T 10}$, is the sum of the novelties of both sessions,

$$
N_{T 10}=N_{T 10_{1 s t}}+N_{T 10_{2 n d}}
$$

The added value using TRIZ10 in terms of practical novelty is defined by

$$
\Delta V_{n}=\frac{N_{T 10}}{N_{\text {own }}}
$$

Finally, the average novelty value of each group defined above will also be calculated,

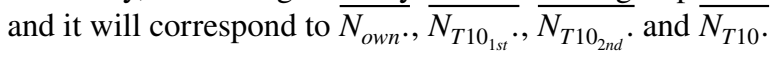

\section{Results and discussion}

In this section, the results obtained from the teaching of the creative technique TRIZ10 are summarized and discussed.

\section{Results of the learning activities of TRIZ10}

This section shows the results of the application of the proposed teaching method of TRIZ10 to a group of 13 students. First, some ideas and sketches made individually by the students in each activity are shown:

Activity 1. Fig. 2 shows 4 examples of schemes made by 4 of the 13 students in the activity 1 , which will be useful for each of them to remember the 10 principles quickly while developing the two sessions of generating ideas based in the inventive principles of TRIZ10. In this way, students will use the TRIZ10 heuristics through sketches, something that favors creative thinking (Yilmaz \& Seifert, 2011).

Activity 2 . In activity 2 , some examples proposed by students about daily technical problems solved with the principles of TRIZ10 are the following:

- Problem: There is a considerable amount of waste. This is solved by recycling and separating waste into different types (glass, organic paper, plastics...).

o Applied principle: Segmentation.

- Problem: Effective teeth cleaning. With electric toothbrushes, greater efficiency is achieved than with conventional toothbrushes.

o Applied principle: Mechanical vibration. 


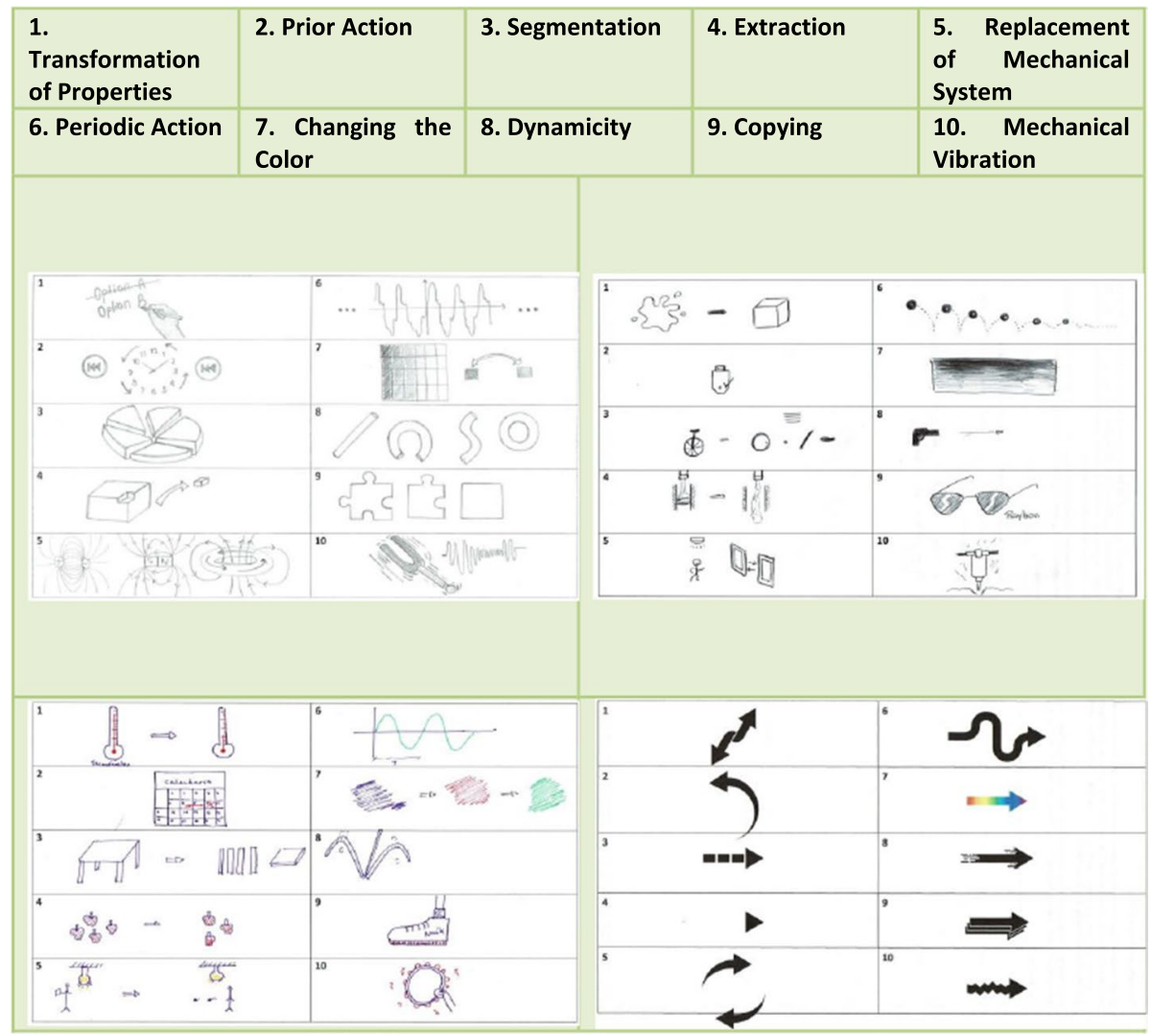

Fig. 2 TRIZ10: examples of individual visual schemes made by students (activity 1)

- Problem: Clearly identify the vehicles used as ambulances to assign priority. Changes color through lighting is achieved.

o Applied principle: Changing the Color.

Activity 3. In activity 3, it was proposed to generate ideas for the "Tupperware" concept using the principles of TRIZ10. Tupperware is a trade mark used to designate a container that is hermetically closed and is used to preserve or carry food, especially cooked food. In general, very novel ideas were obtained; however, they were not always right in their relationship with the principles of TRIZ10. Table 5 shows three real full list of 3 students.

Some of these ideas and the principles behind them are summarized in Table 6, including student sketches.

As a first analysis of the results, in activities 2 and 3, the frequency of the use of the inventive principles of TRIZ10 in both activities has been calculated. Figure 3 shows this relative frequency of use of each principle, in addition to its accumulated value following the order established by TRIZ10.

These results lead us to think of a very similar use of inventive principles by students in both activities. Thus, principles 1,3 , and 5 add up to $50 \%$ of the accumulated value of use in both activities. Further, the frequency of use provided by principle 6, "Periodic 
Table 5 Brainstorming about Tupperware improvements based on TRIZ10 inventive principles (example lists)

\begin{tabular}{lll}
\hline Participant 01 & Participant 09 & Participant 10 \\
\hline It heats up by itself & It heats up by itself & Easy to store \\
Cools itself & Cools itself & It heats up by itself \\
It can be detachable & Non-stick & Transparent \\
Non-deformable & Parallel division & Includes cutlery \\
Eco-sustainable material & Color change with temperature & Detect heat \\
Water resistivity & Cap tied with a string & One piece \\
It cleans itself & Inflatable tupper & Mixer \\
With several compartments & Tupper for class (case size) & Special for children \\
With touch screen & Specific tupper for athletes & With locator \\
Changes color with temperature & With universal cover & With layers \\
\hline
\end{tabular}

Table 6 Brainstorming about Tupperware improvements based on TRIZ10 inventive principles

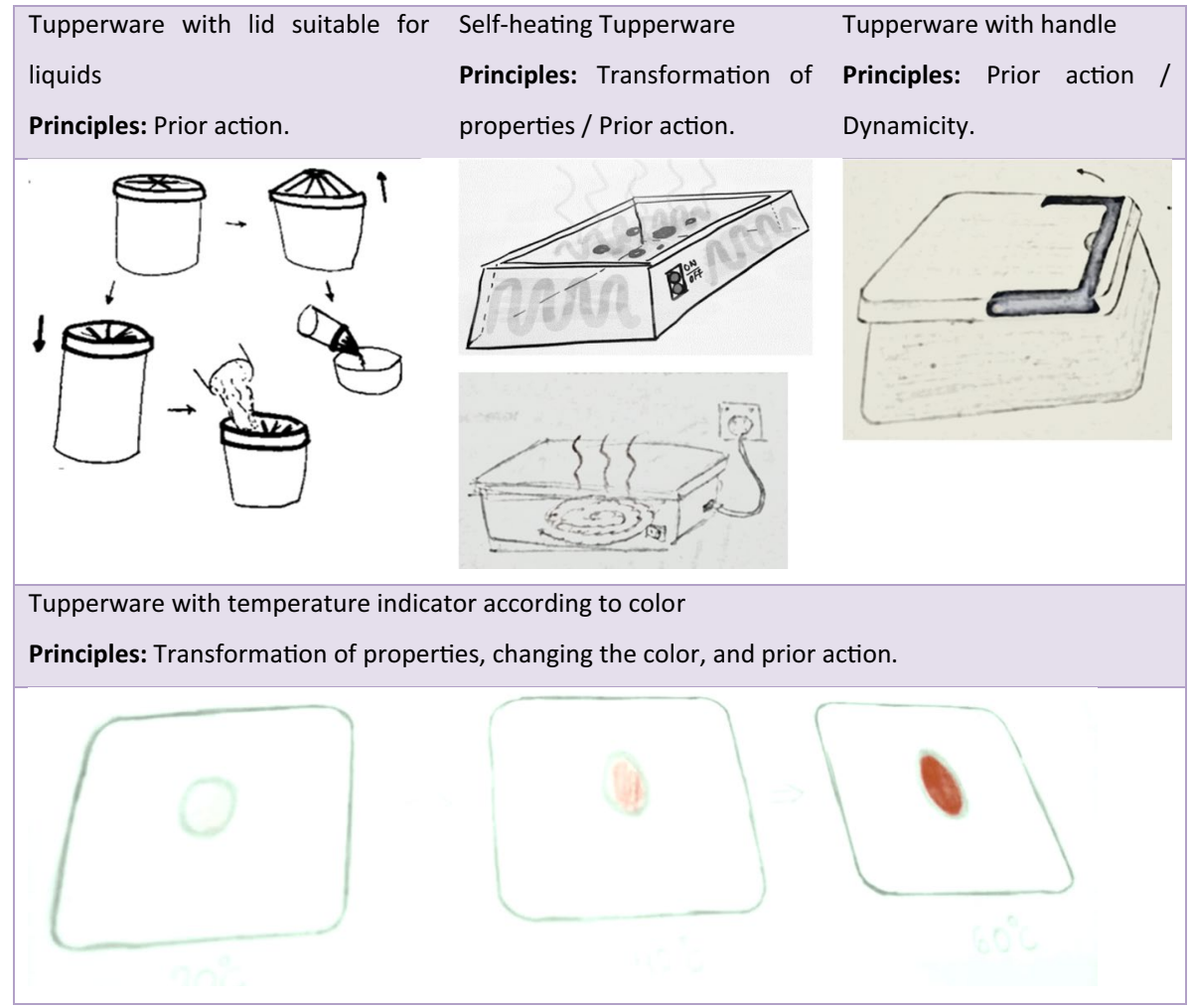

action" is the lowest in both cases. Principle 2, "Preliminary action" also has a relatively low value in both activities despite its high frequency of appearance in the matrix. This 


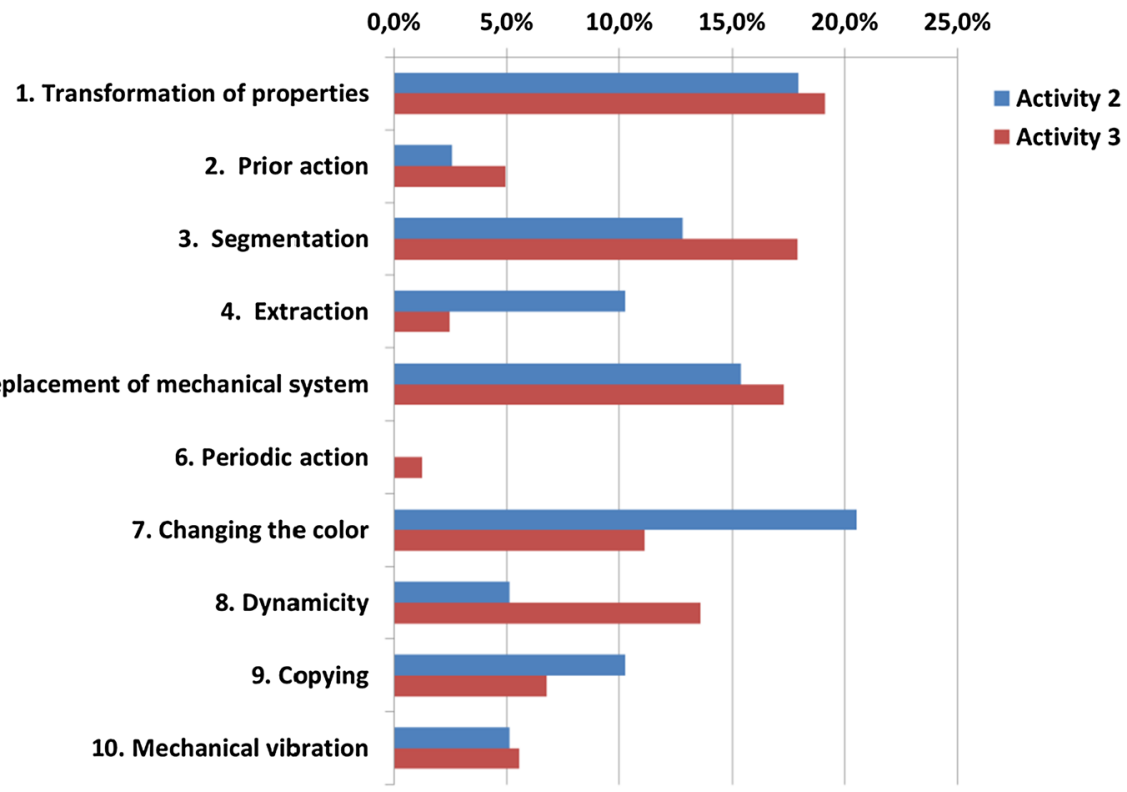

Fig. 3 Inventive principles usage frequency on activities 2 and 3

suggests that a deeper explanation of these principles, 2 and 6, is necessary to overcome the students' resistance to their use.

Activity 4. In this activity, the following problem was proposed to be solved with the principles of TRIZ10: "It is necessary to measure the temperature of specific species of ants with the use of a conventional thermometer". This is a classic problem used in the TRIZ literature (Altshuller, 1997). The students contributed novel ideas that can be classified into three large groups. The first, applied by $6 / 13$ students, who solved it by applying the principle of copying and measuring the average temperature of many ants together. The second group, also used by $6 / 13$ students, modified the conventional thermometer so that the sensor could be adapted to the ants. There was also a student who proposed to attract the ant, with some food (honey) to a tube that could adapt to the conventional thermometer, and once in contact with the ant, introduce that thermometer and measure.

Finally, the efficacy values of the four activities proposed in the teaching and implementation methodology of TRIZ10 to a pilot group of 13 students were calculated. Substituting

Table 7 Efficacy of TRIZ10 activities

\begin{tabular}{lll}
\hline General equation & Application & $\mathrm{SD}(\%)$ \\
$\eta_{A 1}=\frac{\sum_{i=1}^{i=N} \sum_{j=1}^{j=10} P 1_{i j}}{10 N}$ & $\eta_{A 1}=\frac{\sum_{i=1}^{i=13} \sum_{j=1}^{j=10} P 1_{i j}}{10 \cdot 13}=0.785$ & 11.75 \\
$\eta_{A 2}=\frac{\sum_{i=1}^{i=N} \sum_{j=1}^{j=3} P 2_{i j}}{3 N}$ & $\eta_{A 2}=\frac{\sum_{i=1}^{i=13} \sum_{j=1}^{j=3} P 2_{i j}}{3 \cdot 13}=0.885$ & 16.11 \\
$\eta_{A 3}=\frac{\sum_{i=1}^{i=N} P 3_{i}}{10 N}$ & $\eta_{A 3}=\frac{\sum_{i=1}^{i=13} P 3_{i}}{10.13}=0.654$ & 26.94 \\
$\eta_{A 4}=\frac{\sum_{i=1}^{i=N} P_{i}}{10 N}$ & $\eta_{A 4}=\frac{\sum_{i=1}^{i=13} P 4_{i}}{10.13}=0.685$ & 17.48 \\
$\eta_{g}=\sqrt[4]{\prod_{i=1}^{i=4} \eta_{A i}}=\sqrt[4]{\eta_{A 1} \cdot \eta_{A 2} \cdot \eta_{A 3} \cdot \eta_{A 4}}$ & SD mean $=18.07 \%$ \\
\hline
\end{tabular}


the values of each activity in Eqs. (1) to (5) and using $\mathrm{N}=13$, the partial and global efficacy values are obtained, as listed in Table 7.

Analyzing the previous table, a high efficiency is observed in the performance of all the activities; it reaches a global efficiency value of $75 \%$, which is a considerably high value. Each effectiveness, $\boldsymbol{\eta}_{\boldsymbol{A} i}$, could be understood as a measure of the average success of students in make it. Thus, the best scores were reached for activity 2 , with a $88.5 \%$ of success, while the worst was the activity 3 with a $65.4 \%$.

After these activities are related to TRIZ10, the complete TRIZ matrix of contradictions was explained and one more activity was proposed for students to learn how to use this tool and compare their acceptance with what was previously seen. This activity, activity 5 , consisted of solving a proposed problem using the complete contradiction matrix. In this case, the following problem was proposed:

It is necessary to increase the number of packages to be transported in a freight train. Today the wagons are filled completely. A solution is requested that meets the following constraints:

- Do not increase the weight of the car

- Do not vary the external dimensions of the car.

- Increase the number of packages to be transported.

Students had to define the technical contradictions, identify the principles suggested by the complete contradiction matrix, and we apply them to find a solution. To assess students learning level through this activity, $P 5_{i}$, it has been valued both the formulation of the technical contradiction and the application of the principles suggested by the matrix of contradictions. The effectiveness of this activity, $\eta_{A 5}$, can be formulated according to

$$
\eta_{A 5}=\frac{\sum_{i=1}^{i=N} P 5_{i}}{10 N}
$$

Although there were very good ideas, the value obtained was 0.644 . This result suggests greater effectiveness in activities related only to the use of TRIZ10 than to formulate a technical contradiction and resolve it with the use of the contradiction matrix.

\section{TRIZ10's added value}

This section will show the value added by the TRIZ10 creativity technique applied to solving engineering problems within this pilot group of 13 students. In the two brainstorming sessions after training in TRIZ10 (sessions 03 and 04), students are divided into groups, where each student uses the visual TRIZ10 that they had generated in activity 1 . Thus, they develop the visual TRIZ10 individually but each group member uses its visual map in TRIZ10 sessions. The problems were selected and raised by each group (13 students in each group); there were a total of 3 groups of 5, 4, and 4 students. The works selected by each group are as follows:

- BANECO. Design of a new outdoor bench that does not get dirty or is wet. Overall improvement on the design of existing benches.

- EAR BALANCED. Barotrauma is the earache or possible injury caused to the eardrum by rapid changes in pressure. Solve this problem when boarding a plane. 
Table 8 Number of generated ideas of each group

\begin{tabular}{llllll}
\hline Group & \multicolumn{2}{l}{ Own Ideas } & & \multicolumn{2}{l}{ TRIZ10 based Ideas } \\
\cline { 2 - 3 } \cline { 5 - 6 } \cline { 5 - 6 } & $\begin{array}{l}\text { Two sessions } \\
\left(I_{0}\right)\end{array}$ & $\begin{array}{l}\text { First session } \\
\left(\Delta I_{01}\right)\end{array}$ & & $\begin{array}{l}\text { Second session } \\
\left(\Delta I_{02}\right)\end{array}$ & $\begin{array}{l}\text { Sum of } \\
\text { Ideas } \\
\left(I_{T}\right)\end{array}$ \\
\hline 1 & 8 & 7 & 8 & 23 \\
2 & 7 & 10 & 7 & 24 \\
3 & 12 & 7 & 8 & 27 \\
\hline
\end{tabular}

\begin{tabular}{lclc}
\hline Group & \multicolumn{3}{l}{ Added value $\left[\Delta \boldsymbol{V}_{\boldsymbol{f}}\right]$} \\
\cline { 2 - 4 } & First session $(\%)$ & $\begin{array}{l}\text { Second session } \\
(\%)\end{array}$ & Total (\%) \\
\hline 1 & 87,50 & 53,33 & 187,50 \\
2 & 142,86 & 41,18 & 242,86 \\
3 & 58,33 & 42,11 & 125,00 \\
Mean & 93 & 44 & 178 \\
\hline
\end{tabular}

Table 9 TRIZ10 Added value for each group

- PERFECT AIR CIRCULATION. Opening the window to ventilate means energy inefficiency. Design a system that optimizes ventilation in a house and minimizes energy losses.

\section{Fluency}

Table 8 summarizes the compiled total ideas generated both in the two sessions prior to TRIZ10 (own ideas, sessions 01 and 02) and those obtained in each of the two sessions in which students had to rely on the TRIZ10 creativity technique. The total number of ideas obtained by each group to solve their problem is also collected and listed in the table.

Thus, for example, for group 1, we can apply Eq. 8 from the data in Table 8.

$$
\Delta V_{f_{01}}=\frac{\Delta I_{01}}{I_{0}}=\frac{7}{8}=0.875 ; \quad \Delta V_{f_{02}}=\frac{\Delta I_{02}}{I_{0}+\Delta I_{01}}=\frac{8}{8+7}=0.533
$$

Following the example of group 1, we can obtain the global added value by TRIZ10, according to Eq. (8) as

$$
\Delta V_{f}=\frac{\Delta I_{01}+\Delta I_{02}}{I_{0}}=\frac{7+8}{8}=1.875
$$

Further, it can be verified that Eq. (9) is fulfilled, which is a particularization of Eq. (12) for two creative sessions.

$$
\Delta V_{f}=\Delta V_{01}+\Delta V_{02}+\Delta V_{01} \cdot \Delta V_{02}=0.875+0.533+0.875 \cdot 0.533=1.875
$$

Table 9 shows the values added by the use of TRIZ10 to each of the three groups of students. 
Table 10 Absolute novelty values

Table 11 Mean novelty values

\begin{tabular}{|c|c|c|c|c|c|}
\hline & \multicolumn{5}{|c|}{ Absolute Novelty } \\
\hline & $N_{\text {own }}$ & $N_{T 10_{1 s t}}$ & $N_{T 10_{2 n d}}$ & $N_{T 10}$ & $\Delta V_{n}(\%)$ \\
\hline Group01 & 29,0 & 27,0 & 33,0 & 60,0 & 106,9 \\
\hline Group02 & 28,0 & 42,0 & 29,0 & 71,0 & 153,6 \\
\hline Group03 & 40,0 & 25,5 & 27,5 & 53,0 & 32,5 \\
\hline Mean & 32,3 & 31,5 & 29,8 & 61,3 & 97,7 \\
\hline
\end{tabular}

\begin{tabular}{lccccl}
\hline & \multicolumn{3}{l}{ Mean Novelty } & & \\
\cline { 2 - 6 } & $O w n$ & $T 10_{1 s t}$ & $T 10_{2 n d}$ & $T 10$ & Improvement (\%) \\
\hline Group01 & 3,52 & 3,76 & 4,58 & 4,17 & 18,6 \\
Group02 & 4,00 & 4,20 & 4,14 & 4,17 & 4,3 \\
Group03 & 3,33 & 3,64 & 3,44 & 3,54 & 6,2 \\
Mean & 3,6 & 3,9 & 4,1 & 4,0 & 9,7 \\
\hline
\end{tabular}

It is observed that the average added value for the use of TRIZ10 is $178 \%$, which is almost double the additional ideas generated when using this creativity technique.

Other idea generation methods, such as "creative heuristic" used by Gray et al. (Gray et al., 2019) also obtained 50\% improvement in fluency after own ideas brainstorming session. However, other experiences (see Table 1) show a decrement in fluency. Nevertheless, it is not possible a direct comparison because the methodologies and capacitation times are different. Creative techniques time instruction of these authors varies from $10 \mathrm{~min}$ (Gray et al., 2019) to $30 \mathrm{~min}$ (Dumas \& Schmidt, 2015; Dumas et al., 2016) and other times not specified (Chang et al., 2016). TRIZ10 approach instruction includes $30 \mathrm{~min}$ of lecture and 4 activities to fix the theory. First two activities ( 1 and 2$)$ are previous to the first TRIZ10 idea generation session, and the other two activities ( 3 and 4 ) are before the second TRIZ10 session.

\section{Practical novelty}

Following Eqs. (13)-(21), the results obtained from applying the proposed methodology to the three groups of students is shown and discussed. Table 10 lists the results of the assessment of practical novelty values. In general, a very high increase in the degree of total novelty is observed with the use of TRIZ10. The average values indicate that each session of TRIZ10 is equivalent to the two sessions of generating own ideas in terms of novelty, i.e., the novelty of the ideas produced with TRIZ10, compared to their own, is almost double.

Table 11 shows the average values of the novelty of the ideas generated without the knowledge of TRIZ10 (Own) and in the two sessions of TRIZ10 separately, and their average. In this experience, it can be said that the novelty is greater in all ideas generated in the sessions of TRIZ10 compared to previous ideas. The average degree of improvement in terms of novelty per idea is approximately $10 \%$. 
Novelty improvement tendency is consistent with other authors (Chang et al., 2016; Dumas \& Schmidt, 2015; Dumas et al., 2016; Gray et al., 2019) who use the exhaustion method. In Table 1, several works shows an increment of novelty with TRIZ instruction.

The ideas with major practical novelty for each problem are listed below:

- BANECO:

o Implement a bank car wash system.

- Average value of practical novelty: 5.67;

- Session: First TRIZ10 (session 03).

p Walls with benches inside.

- Average value of practical novelty: 5.67;

- Session: Second TRIZ10 (session 04).

q Seat vibration to remove water from the benches.

- Average value of practical novelty: 5.67;

- Session: Second TRIZ10 (session 04).

- EAR BALANCED.

o Individual earmuff, within which there is an individual pressure regulator.

- Average value of practical novelty: 5.67;

- Session: Second TRIZ10 (session 04).

$\mathrm{p}$ Simulation of ear of birds flying at high altitude.

- Average value of practical novelty: 5.67;

- Session: First TRIZ10 (session 03).

q Neck cushion with vibration and heat.

- Average value of practical novelty: 5.67;

- Session: Second TRIZ10 (session 04).

- PERFECT AIR CIRCULATION:

o Clean the air through a greenhouse inside the building.

- Average value of practical novelty: 7;

- Session: Second TRIZ10 (session 04).

p Porous wall with heating inside the wall to heat the air that passes through.

- Average value of practical novelty: 5.67;

- Session: Own idea (sessions 01/02).

q Store air in a system that keeps it clean. This is the air that will be introduced into the room when ventilating. It could be a common system to a block of flats.

- Average value of practical novelty: 5;

- Session: First TRIZ10 (session 03). 

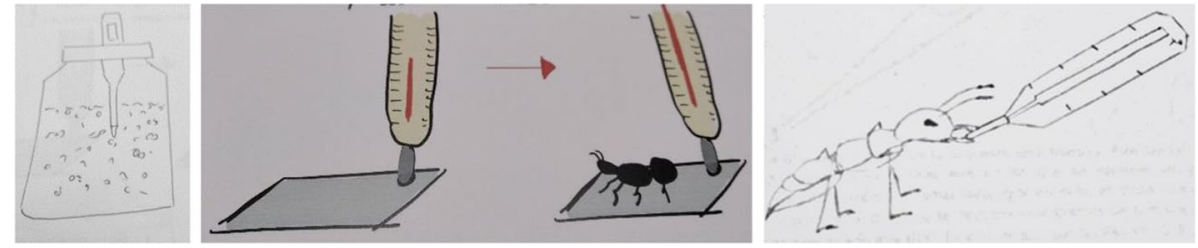

Fig. 4 Examples of three solutions groups in activity

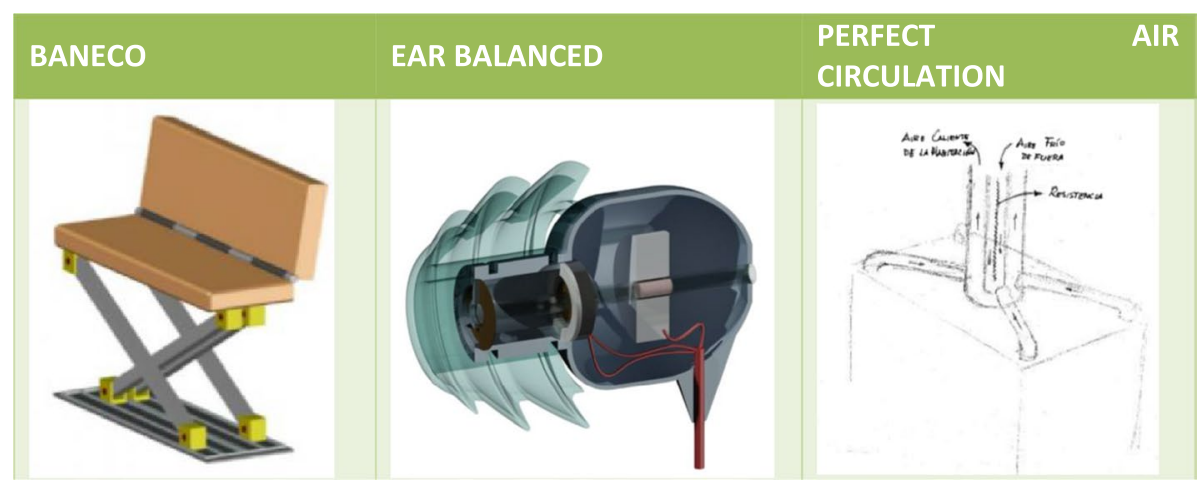

Fig. 5 Final group designs

Finally, by means of weighting methods such as the decision matrices type QFD (quality function deployment) (Akao, 1993) and the DATUM (Pugh, 1996), each group selected their solution to be develop based on one or several ideas of those previously generated. These ideas selected by each group are provided below:

- BANECO. Bench with folding backrest that can be stored on the floor.

- EAR BANLANCED. Manual pressure regulator, in the form of a sonotone device, but changing the system to alter the pressure.

- PERFECT AIR CIRCULATION. Air flow in the ventilation of the room will be conducted through a tube with a resistance inside the tube. The air that enters is heated to avoid sudden changes in temperature within the room and with it, a greater energy expenditure to stabilize that temperature is required.

Figures 4 and 5 shows an image of the final design selected by the students.

\section{Scope and limitations of this study}

In this research, one of the main assumptions was that TRIZ10 could facilitate the use of TRIZ as a part of the subject. Results shows that TRIZ10 allows a successful learning about the usage of the 10 inventive principles more probable to find in contradiction matrix (Akao 1993). On the other hand, based on results of activity 5, for carrying out the teaching of TRIZ with its 40 inventive principles and the usage of contradiction matrix, there will be necessary to spend more time for reaching a higher level of learning by students. 
These results are agree with the conclusions of Ilevbare et al. (2013) about the complexity of learning TRIZ.

On the other hand, results show the reached fluency was higher than other presented by other authors which used TRIZ (Altshuller 2002; Arcidiacono \& Bucciarelli 2016). In these studies, in fact, the fluency decreased. This result could be explained as contradiction matrix only suggest up to 4 principles for each technical contradiction and TRIZ10 allows to use 10 inventive principles. However, the novelty/originality has the same tendency than using TRIZ (Altshuller 2002; Arcidiacono \& Bucciarelli 2016; Belski 2015).

The main limitation of this study is that the number of groups is small. Further studies with larger samples are required to establish the claims derived of this first study. The number of students in each group could be studied too.

Other limitation is that some of these inventive principles are usable only in technical problems. Other principles can be applied in any field (i.e., segmentation). However, it could be adapted to non-technical topics by selecting the 10 more probable principles that are non-so technical.

\section{Conclusions}

The methodology and application of a simplified TRIZ methodology was presented. This methodology was well received by the group of students oriented to the teaching, and the use of the TRIZ10 creativity technique helped them achieve an overall effectiveness of $75 \%$ for the four activities through which the students learned this technique. This average value was greater than that obtained in an additional activity (activity 5), wherein students used the complete TRIZ contradiction matrix.

As future scope, we observed that two inventive principles-6 ("Periodic Action") and 2 ("Preliminary Action")—-were not used as often by students, and these will be elaborated on in the next course.

However, the learning and application of the TRIZ10 technique towards the resolution of technical problems allowed tripling the number of ideas for the evaluation because they generated twice as many ideas compared to the number of ideas before knowing this technique. In addition, the average degree of novelty of these ideas is $10 \%$ higher than those previously generated. These two results obtained in a small group of students suggest that a higher number of ideas and a higher degree of novelty will help increase the competitiveness of the technical solutions of future engineers. These results thus suggest that this methodology is suitable for learning TRIZ10. On the other hand, this successful proof of concept of TRIZ10 approach learning and application lead us about a TRIZ10 approach could be an effective creativity technique for engineering students, which allows an increasing number of innovative ideas to be generated.

As future work, this methodology will be improved with lessons learned in this first step and applied to more groups to assure that these results can be reproduced. On the other hand, this methodology of learning and applying TRIZ10 technique could be applied alone as a creative technique not only for solving problems but also for generating ideas (i.e., improving an existing object). Furthermore, TRIZ10 could be applied in different fields and subjects.

Moreover, we are studying to improve this methodology by using easy models and prototypes for enhancing creativity, even for complementing the visual TRIZ10 developed by students in activity 1 . 
Acknowledgements The authors would like to express their greatest appreciation to all the students who participated in this pilot study of the subject of Methodology of the design and the creativity.

Funding Open Access funding provided thanks to the CRUE-CSIC agreement with Springer Nature.

\section{Declarations}

Conflict of interest The authors declare that they have no conflict of interest.

Open Access This article is licensed under a Creative Commons Attribution 4.0 International License, which permits use, sharing, adaptation, distribution and reproduction in any medium or format, as long as you give appropriate credit to the original author(s) and the source, provide a link to the Creative Commons licence, and indicate if changes were made. The images or other third party material in this article are included in the article's Creative Commons licence, unless indicated otherwise in a credit line to the material. If material is not included in the article's Creative Commons licence and your intended use is not permitted by statutory regulation or exceeds the permitted use, you will need to obtain permission directly from the copyright holder. To view a copy of this licence, visit http://creativecommons.org/licenses/by/4.0/.

\section{References}

Akao, Y. (1993). Despliegue de funciones de calidad qfd (Edición: 1.). Madrid: Prod. Press.

Altshuller, G. (1997). Introducción A La Innovación Sistemática: TRIZ. De Pronto, Apareció El Inventor. Paterna.

Altshuller, G. (2002). 40 Principles: TRIZ Keys to Innovation. Technical Innovation Center, Inc.

Arcidiacono, G., \& Bucciarelli, L. (2016). TRIZ: Engineering methodologies to improve the process reliability. Quality and Reliability Engineering International, 32(7), 2537-2547. https://doi.org/10. 1002/qre. 1955

Belski, I. (2015). TRIZ Education: Victories, Defeats and Challenges. Educational Technologies (Russian: Образовательные технологии), 83-92.

Belski, I., Baglin, J., \& Harlim, J. (2013). Teaching TRIZ at University: A longitudinal study. International Journal of Engineering Education, 29, 346-354.

Bertoncelli, T., Mayer, O., \& Lynass, M. (2016). Creativity, learning techniques and TRIZ. Procedia CIRP, 39, 191-196. https://doi.org/10.1016/j.procir.2016.01.187

Borgianni, Y., Frillici, F., \& Rotini, F. (2018). How problems are solved in TRIZ literature: the need for alternative techniques to individuate the most suitable Inventive Principles. Presented at the 17th ETRIA TRIZ Future Conference, Lappeenranta, Finland.

Bourgeois-Bougrine, S., Buisine, S., Vandendriessche, C., Glaveanu, V., \& Lubart, T. (2017). Engineering students' use of creativity and development tools in conceptual product design: What, when and how? Thinking Skills and Creativity, 24, 104-117. https://doi.org/10.1016/j.tsc.2017.02.016

Bozkurt Altan, E., \& Tan, S. (2020). Concepts of creativity in design based learning in STEM education. International Journal of Technology and Design Education. https://doi.org/10.1007/ s10798-020-09569-y

Cano-Moreno, J. D., \& Cabanellas Becerra, J. M. (2018a). TRIZ: Probabilistic approach for solving technical problems. DYNA Management, Enero-Diciembre 2018, 6(1), 9p. http://dx.doi.org/https:// doi.org/10.6036/8990

Cano-Moreno, J. D., \& Cabanellas Becerra, J. M. (2018b). TRIZ10. The decalogue of technical creativity. DYNA, 93(6), 586. http://dx.doi.org/https://doi.org/10.6036/8997

Chang, Y.-S., Chien, Y.-H., Yu, K.-C., Chu, Y.-H., \& Chen, M. Y. (2016). Effect of TRIZ on the creativity of engineering students. Thinking Skills and Creativity, 19, 112-122. https://doi.org/10.1016/j. tsc. 2015.10.003

Corazza, G. E., \& Agnoli, S. (2018). The Creative Process in Science and Engineering. In T. Lubart (Ed.), The Creative Process: Perspectives from Multiple Domains (pp. 155-180). London: Palgrave Macmillan UK. https://doi.org/10.1057/978-1-137-50563-7_6

Cortes Robles, G., Negny, S., \& Le Lann, J. M. (2009). Case-based reasoning and TRIZ: A coupling for innovative conception in Chemical Engineering. Chemical Engineering and Processing: Process Intensification, 48(1), 239-249. https://doi.org/10.1016/j.cep.2008.03.016 
Daly, S., Christian, J., Yilmaz, S., Seifert, C., \& Gonzalez, R. (2012a). Assessing design heuristics for idea generation in an introductory engineering course. International Journal of Engineering Education, 28, 463-473.

Daly, S. R., Yilmaz, S., Christian, J. L., Seifert, C. M., \& Gonzalez, R. (2012b). Design heuristics in engineering concept generation. Journal of Engineering Education, 101(4), 601-629. https://doi. org/10.1002/j.2168-9830.2012.tb01121.x

Deci, E. L., \& Ryan, R. M. (2012). Self-determination theory. In Handbook of theories of social psychology (P. A. M. Van Lange, A. W. Kruglanski, E. T. Higgins., pp. 416-437). Thousand Oaks: Sage Social Psychology Program.

Diedrich, J., Benedek, M., Jauk, E., \& Neubauer, A. (2015). Are creative ideas novel and useful? Psychology of Aesthetics, Creativity, and the Arts, 9, 35-40. https://doi.org/10.1037/a0038688

Dumas, D., \& Schmidt, L. (2015). Relational reasoning as predictor for engineering ideation success using TRIZ. Journal of Engineering Design, 26(1-3), 74-88. https://doi.org/10.1080/09544828. 2015.1020287

Dumas, D., Schmidt, L. C., \& Alexander, P. A. (2016). Predicting creative problem solving in engineering design. Thinking Skills and Creativity, 21, 50-66. https://doi.org/10.1016/j.tsc.2016.05.002

European Advisory Commission (EAC). (2018, September 21). European Credit Transfer and Accumulation System (ECTS). Education and Training - European Commission. Text. https://ec.europa. eu/education/resources-and-tools/european-credit-transfer-and-accumulation-system-ects_en. Accessed 2 October 2020

Goldschmidt, G. (2001). Visual Analogy -a Strategy for Design Reasoning and Learning. Visual Databases in Architecture: Recent Advances in Design and Decision Making. https://doi.org/10.1016/ B978-008043868-9/50009-7

Gray, C. M., McKilligan, S., Daly, S. R., Seifert, C. M., \& Gonzalez, R. (2019). Using creative exhaustion to foster idea generation. International Journal of Technology and Design Education, 29(1), 177-195. https://doi.org/10.1007/s10798-017-9435-y

Guilford, J. P. (1950). Creativity. American Psychologist, 5(9), 444-454. https://doi.org/10.1037/h0063 487

Higgins, J. M. (1994). 101 Creative Problem Solving Techniques: The Handbook of New Ideas for Business. New Management Publishing Company.

Ilevbare, I. M., Probert, D., \& Phaal, R. (2013). A review of TRIZ, and its benefits and challenges in practice. Technovation, 33(2), 30-37. https://doi.org/10.1016/j.technovation.2012.11.003

Sternberg, J. R. (2006). The Nature of Creativity. Creativity Research Journal, 18, 87-98. https://doi. org/10.1207/s15326934crj1801_10

John-Steiner, V., \& Mahn, H. (1996). Sociocultural approaches to learning and development: A Vygotskian framework. Educational Psychologist, 31(3-4), 191-206. https://doi.org/10.1080/00461520. 1996.9653266

Lee, J. W., Ostrowski, A., Daly, S. R., Huang-Saad, A., \& Seifert, C. M. (2019). Idea generation in biomedical engineering courses using Design Heuristics. European Journal of Engineering Education, 44(3), 360-378. https://doi.org/10.1080/03043797.2018.1514368

Ling, D. (2015). Complete Design Thinking Guide for Successful Professionals. Singapore.

Litcanu, M., Prostean, O., Oros, C., \& Mnerie, A. V. (2015). Brain-writing vs. brainstorming case study for power engineering education. Procedia - Social and Behavioral Sciences, 191, 387-390. https:// doi.org/10.1016/j.sbspro.2015.04.452

Livotov, P., Mas'udah, \& Chandra Sekaran, A. P. (2018). On the Efficiency of TRIZ Application for Process Intensification in Process Engineering. In D. Cavallucci, R. De Guio, \& S. Koziołek (Eds.), Automated Invention for Smart Industries (pp. 126-140). Springer International Publishing.

Moreno, D. P., Hernández, A. A., Yang, M. C., Otto, K. N., Hölttä-Otto, K., Linsey, J. S., et al. (2014). Fundamental studies in Design-by-Analogy: A focus on domain-knowledge experts and applications to transactional design problems. Design Studies, 35(3), 232-272. https://doi.org/10.1016/j. destud.2013.11.002

Oman, S. K., Tumer, I. Y., Wood, K., \& Seepersad, C. (2013). A comparison of creativity and innovation metrics and sample validation through in-class design projects. Research in Engineering Design, 24(1), 65-92. https://doi.org/10.1007/s00163-012-0138-9

Poppa, T., \& Bechara, A. (2018). The somatic marker hypothesis: Revisiting the role of the 'body-loop' in decision-making. Current Opinion in Behavioral Sciences, 19, 61-66. https://doi.org/10.1016/j. cobeha.2017.10.007

Pugh, S. A. (1996). Concept Selection: A Method that Works. 
Ranjan, B. S. C., Siddharth, L., \& Chakrabarti, A. (2018). A systematic approach to assessing novelty, requirement satisfaction, and creativity. AI EDAM, 32(4), 390-414. https://doi.org/10.1017/S0890 060418000148

Sancibrian, R., Gonzalez-Sarabia, E., San-José, J. T., Llata, J. R., \& Larrauri, M. (2019). DESIGN BY ANALOGY IN ENGINEERING EDUCATION: A METHOD TO IMPROVE CREATIVE IDEAS. INTED2019 Proceedings, 6268-6274. Presented at the 13th International Technology, Education and Development Conference.

Sarkar, P., \& Chakrabarti, A. (2011). Assessing design creativity. Design Studies, 32(4), 348-383. https://doi.org/10.1016/j.destud.2011.01.002

Scott, G., Leritz, L. E., \& Mumford, M. D. (2004). The effectiveness of creativity training: A quantitative review. Creativity Research Journal, 16(4), 361-388. https://doi.org/10.1080/10400410409534549

Shuell, T. J. (1990). Phases of Meaningful Learning. Review of Educational Research, 60(4), 531-547. https://doi.org/10.3102/00346543060004531

SolidCreativity (2014), TRIZ Matrix, Contradictions table, overcome contradiction with TRIZ. (n.d.). http://www.triz40.com/aff_Matrix_TRIZ.php. Retrieved 31 July 2018.

Sternberg, R. J., \& Lubart, T. I. (1998). The Concept of Creativity: Prospects and Paradigms. In R. J. Sternberg (Ed.), Handbook of Creativity (pp. 3-15). Cambridge: Cambridge University Press. https://doi.org/10.1017/CBO9780511807916.003

Tatarkiewicz, W. (2004). Historia De Seis Ideas. TECNOS. https://www.goodreads.com/book/show/ 2543406.Historia_De_Seis_Ideas. Retrieved 5 August 2018

Tessari, R. K., \& De Carvalho, M. A. (2015). Compilation of Heuristics for Inventive Problem Solving. Procedia Engineering, 131, 50-70. https://doi.org/10.1016/j.proeng.2015.12.347

Thompson, G., \& Lordan, M. (1999). A review of creativity principles applied to engineering design. Proceedings of the Institution of Mechanical Engineers, Part E: Journal of Process Mechanical Engineering, 213(1), 17-31. https://doi.org/10.1243/0954408991529960

Toh, C. A., \& Miller, S. R. (2016). Creativity in design teams: The influence of personality traits and risk attitudes on creative concept selection. Research in Engineering Design, 27(1), 73-89. https://doi.org/ 10.1007/s00163-015-0207-y

Torrance, E. P. (1962). Guiding creative talent. Hoboken: Prentice-Hall, Inc. https://doi.org/10.1037/ 13134-000

Turner, S. (2009). ASIT - a problem solving strategy for education and eco-friendly sustainable design. International Journal of Technology and Design Education, 19(2), 221-235. https://doi.org/10.1007/ s10798-008-9080-6

Vygotsky, L. S. (2004). Interaction between learning and development. In Mind and society (M. Gauvain\&M. Cole., pp. 29-36). New York, NY, US: W.H. Freeman and Company.

Wu, T.-T., \& Wu, Y.-T. (2020). Applying project-based learning and SCAMPER teaching strategies in engineering education to explore the influence of creativity on cognition, personal motivation, and personality traits. Thinking Skills and Creativity, 35, 100631. https://doi.org/10.1016/j.tsc.2020.100631

Yilmaz, S., \& Seifert, C. M. (2011). Creativity through design heuristics: A case study of expert product design. Design Studies, 32(4), 384-415. https://doi.org/10.1016/j.destud.2011.01.003

Publisher's Note Springer Nature remains neutral with regard to jurisdictional claims in published maps and institutional affiliations. 